\title{
Technical note: Comparison of methane ebullition modelling approaches used in terrestrial wetland models
}

\author{
Olli Peltola ${ }^{1}$, Maarit Raivonen ${ }^{1}$, Xuefei Li $^{1}$, and Timo Vesala ${ }^{1,2}$ \\ ${ }^{1}$ Institute for Atmospheric and Earth System Research/Physics, Faculty of Science, University of Helsinki, \\ P.O. Box 68, 00014 Helsinki, Finland \\ ${ }^{2}$ Institute for Atmospheric and Earth System Research/Forest Sciences, Faculty of Agriculture and Forestry, \\ University of Helsinki, P.O. Box 27, 00014 Helsinki, Finland
}

Correspondence: Olli Peltola (olli.peltola@helsinki.fi)

Received: 30 June 2017 - Discussion started: 4 July 2017

Revised: 14 December 2017 - Accepted: 28 December 2017 - Published: 15 February 2018

\begin{abstract}
Emission via bubbling, i.e. ebullition, is one of the main methane $\left(\mathrm{CH}_{4}\right)$ emission pathways from wetlands to the atmosphere. Direct measurement of gas bubble formation, growth and release in the peat-water matrix is challenging and in consequence these processes are relatively unknown and are coarsely represented in current wetland $\mathrm{CH}_{4}$ emission models. In this study we aimed to evaluate three ebullition modelling approaches and their effect on model performance. This was achieved by implementing the three approaches in one process-based $\mathrm{CH}_{4}$ emission model. All the approaches were based on some kind of threshold: either on $\mathrm{CH}_{4}$ pore water concentration (ECT), pressure (EPT) or free-phase gas volume (EBG) threshold. The model was run using 4 years of data from a boreal sedge fen and the results were compared with eddy covariance measurements of $\mathrm{CH}_{4}$ fluxes.

Modelled annual $\mathrm{CH}_{4}$ emissions were largely unaffected by the different ebullition modelling approaches; however, temporal variability in $\mathrm{CH}_{4}$ emissions varied an order of magnitude between the approaches. Hence the ebullition modelling approach drives the temporal variability in modelled $\mathrm{CH}_{4}$ emissions and therefore significantly impacts, for instance, high-frequency (daily scale) model comparison and calibration against measurements. The modelling approach based on the most recent knowledge of the ebullition process (volume threshold, EBG) agreed the best with the measured fluxes $\left(R^{2}=0.63\right)$ and hence produced the most reasonable results, although there was a scale mismatch between the measurements (ecosystem scale with heterogeneous ebullition locations) and model results (single horizontally ho-
\end{abstract}

mogeneous peat column). The approach should be favoured over the two other more widely used ebullition modelling approaches and researchers are encouraged to implement it into their $\mathrm{CH}_{4}$ emission models.

\section{Introduction}

A large fraction of methane $\left(\mathrm{CH}_{4}\right)$ emitted from wetlands to the atmosphere is released in rapid bubbling events, during which part of the biogenic gas bubbles trapped below the surface are released and transported quickly to the atmosphere. This emission route, called ebullition, has been observed to make a significant contribution to the total $\mathrm{CH}_{4}$ emissions in some wetlands (e.g. Tokida et al., 2007; Yu et al., 2014; Christensen et al., 2003), whereas the rest of the emissions are emitted more steadily via diffusion or plant-mediated transport (e.g. Le Mer and Roger, 2001). Rapid emission of $\mathrm{CH}_{4}$ in ebullition events allows the emitted $\mathrm{CH}_{4}$ to bypass an oxic zone where the transported $\mathrm{CH}_{4}$ might have been otherwise oxidized prior to reaching the atmosphere (Rosenberry et al., 2006). A characteristic feature of ebullition is that it takes place in sporadic events that are irregularly distributed in space and time (e.g. Klapstein et al., 2014; Tokida et al., 2007). Thus, their long-term measurement and quantification in the field has proven to be very challenging and hence a complete understanding of the mechanisms controlling ebullition is still lacking.

Based on the current knowledge an episodic ebullition event takes place when a gaseous-phase gas volume at a cer- 
tain level below the surface reaches a critical threshold, after which the excess gas is released in an ebullition event. This follows from the fact that for big enough gas bubbles the buoyancy forces exceed the retention forces that have been keeping the entrapped bubbles in place and hence they start to ascend towards the surface (Fechner-Levy and Hemond, 1996). Generally, the critical volumetric threshold for triggering ebullition is considered to be around $10 \%$ (at maximum $20 \%$ ) of the total peat volume (Rosenberry et al., 2006). Based on the existing empirical evidence the released gas bubbles consist largely of $\mathrm{CH}_{4}(20-80 \%$ of the bubble gas) (Waddington et al., 2009; Kellner et al., 2006; Tokida et al., 2005; Glaser et al., 2004; Walter et al., 2008) and the rest is nitrogen $\left(\mathrm{N}_{2}\right)$, oxygen $\left(\mathrm{O}_{2}\right)$ and carbon dioxide $\left(\mathrm{CO}_{2}\right)$ (Tokida et al., 2005; Kellner et al., 2006; Walter et al., 2008), which suggests that the bubbles originate from conditions with relatively high pore water $\mathrm{CH}_{4}$ concentrations. The gas bubbles may form under anaerobic conditions in which high pore water concentrations facilitate the formation and buildup of gas-phase bubbles. Existence of bubble formation nuclei is not considered to limit bubble formation.

Considering the ideal gas law and Henry's law, the gasphase bubble volume can be modified by (1) pressure, (2) temperature or (3) pore water concentration changes (Fechner-Levy and Hemond, 1996). The effect of pressure can be further divided into atmospheric and hydrostatic (i.e. the weight of the water column above) pressure. Hence, if the bubble volume threshold is also considered, an ebullition event may be triggered by decreasing atmospheric pressure, water table depth (WTD), increasing peat temperature or pore water $\mathrm{CH}_{4}$ concentration. Out of these, decreasing atmospheric pressure has been most often reported to trigger ebullition (Tokida et al., 2007, 2005; Waddington et al., 2009; Yu et al., 2014; Strack et al., 2005; Kellner et al., 2006), whereas some studies have also reported the effect of WTD (Moore et al., 1990) and temperature (Waddington et al., 2009; Kellner et al., 2006; Yu et al., 2014). Other forcings (e.g. increasing pressure, wind speed) have also been linked with ebullition (Goodrich et al., 2011; Comas et al., 2011).

According to a recent review by $\mathrm{Xu}$ et al. (2016) most (24 out of 40) of the process-based models focusing on $\mathrm{CH}_{4}$ cycling incorporate some kind of an approach to model ebullition. In a seminal modelling paper by Walter and Heimann (2000) a simple approach was adopted: if pore water $\mathrm{CH}_{4}$ concentration exceeded a certain threshold value, then the excess $\mathrm{CH}_{4}$ was directly released to the atmosphere. Thereafter, the approach has been adopted with slight modifications to several $\mathrm{CH}_{4}$ models and can be regarded as the most widespread method to model ebullition. The most common alteration of the approach is to estimate the concentration threshold based on $\mathrm{CH}_{4}$ solubility (e.g. Wania et al., 2010; Riley et al., 2011).

Pore water concentration threshold was the most widely used ebullition modelling approach in the models reviewed by Xu et al. (2016). It was incorporated in 16 out 24 models
(67\%) that included this transport route. However, based on current knowledge this approach can be questioned since it lacks almost all of the details outlined above about the ebullition process and hence could result in an unrealistically modelled process. Other ebullition modelling approaches have been implemented as well. For instance, Grant (1998), Tang et al. (2010) and Raivonen et al. (2017) triggered ebullition if the total pressure of water-dissolved gases exceeded the ambient pressure at a given depth, whereas in some studies (Segers et al., 2001; Granberg et al., 2001; Zhang et al., 2012) ebullition was modelled using a threshold for gaseous volume at a certain depth below surface.

This study was motivated by the fact that in many processbased models ebullition is modelled in a manner that does not agree with the current knowledge of the process. Hence the models possibly produce erroneous ebullition fluxes and thus may for instance bias the modelled annual $\mathrm{CH}_{4}$ emissions and produce a mismatch between modelled and measured $\mathrm{CH}_{4}$ fluxes. The aim of this study is to compare three ebullition modelling approaches that are based on pore water concentration (Sect. 2.1), pressure (Sect. 2.2) and gaseous volume (Sect. 2.3) thresholds. This is achieved by implementing the three approaches in one process-based model called HIMMELI (Raivonen et al., 2017) and running the model with the same input data and only altering the ebullition modelling approach. We aim to characterize the differences in (1) number, timing and depth below peat surface of the modelled ebullition events, (2) variables causing the events and (3) modelled $\mathrm{CH}_{4}$ flux to the atmosphere. In addition, the performance of the volume threshold approach using different model parameters is evaluated. Hypothetically, the approach based on gas volume threshold should produce the most reasonable results since it resembles the current knowledge of ebullition the most. The main aim of this technical note is to report the differences between ebullition modelling approaches and to promote the usage of physically sound methods in future $\mathrm{CH}_{4}$ modelling studies.

\section{Materials and methods}

In this study a model concentrated on $\mathrm{CH}_{4}$ cycling is run using data from a boreal fen to study the differences between three ebullition modelling approaches. The model and measurement data are described below. The following nomenclature is used throughout this study: "ebullition event" is used to define an episode during which concentration (ECT), pressure (EPT) or bubble volume (EBG) threshold was exceeded at a certain depth; "ebullition" is defined as the upward transport of $\mathrm{CH}_{4}$ via the ebullition process to the lowest air filled pore space; and "direct ebullition to the surface" is the ebullition flux directly to the atmosphere. Direct ebullition to the surface can take place only when the water table level is at the surface or above it. 


\subsection{Process-based model HIMMELI}

In this study a process-based model, HIMMELI, provided a framework used to compare the three ebullition modelling approaches. The model is described elsewhere (Raivonen et al., 2017) and thus the description is not repeated in detail here. In short, the 1-D model estimates sources, sinks and interactions between three substances, namely $\mathrm{CO}_{2}, \mathrm{O}_{2}$ and $\mathrm{CH}_{4}$ in a vertically layered peat-water-air column. HIMMELI incorporates the following reaction-diffusion equation to model the temporal evolution of $\mathrm{CH}_{4}$ concentration $\left(c_{\mathrm{w}}\right.$, $\mathrm{mol} \mathrm{m}^{-3}$ ) in the peat pore water:

$$
\begin{aligned}
\frac{\partial c_{\mathrm{W}}(t, z)}{\partial t}= & -Q_{\mathrm{diff}}(t, z)-Q_{\mathrm{plant}}(t, z) \\
& -Q_{\mathrm{ebu}}(t, z)+R_{\mathrm{prod}}(t, z)-R_{\mathrm{oxi}}(t, z),
\end{aligned}
$$

where $Q_{\text {diff }}$ is the diffusive flux of $\mathrm{CH}_{4}$ in the peat, $Q_{\text {plant }}$ is the transport rate of $\mathrm{CH}_{4}$ via plant roots, $Q_{\text {ebu }}$ is the transport rate of $\mathrm{CH}_{4}$ via ebullition, $R_{\text {prod }}$ is the production rate of $\mathrm{CH}_{4}$ and $R_{\text {oxi }}$ is the rate at which oxidation removes $\mathrm{CH}_{4}$ from the pore water. The units for the terms on the right-hand side of Eq. (1) are mol m${ }^{-3} \mathrm{~s}^{-1}$. In this study we altered $Q_{\text {ebu }}$ between the runs; the other terms were not modified.

The model is driven with peat temperature $(T)$, atmospheric pressure, WTD, leaf area index (LAI) of gastransporting vegetation and rate of anoxic soil respiration. We ran the model for the Siikaneva peatland site (Rinne et al., 2007) using measured $T$, atmospheric pressure, WTD, simulated LAI and anoxic respiration as input. The latter was simulated similarly to the study by Susiluoto et al. (2017) in which HIMMELI was combined with a model of anoxic respiration. The model simulated respiration as a fraction of net primary productivity (NPP) plus temperature-dependent peat decay. The former was distributed vertically according to the root distribution while the latter was distributed evenly into the peat layers below water level; therefore, the main factor driving the anoxic respiration was NPP modelled for Siikaneva. We used the same calibrated parameter values as in the discussion paper of Raivonen et al. (2017). The model has been calibrated in Susiluoto et al. (2017); however, parameters used in the different ebullition modelling approaches (see below) were not calibrated. Instead, values found from the literature were used for the ebullition modelling approaches since this way the results are more comparable across studies (e.g. with Wania et al., 2010). Furthermore, when using literature values the results are truly related to differences between the approaches and not related to differences between calibrations. In this study HIMMELI was run using a $2 \mathrm{~m}$ thick peat column with 10 layers; therefore, each layer was $0.2 \mathrm{~m}$ thick. The model output time step is 1 day, but the model uses a shorter internal time step in order to ensure numerical stability.

In HIMMELI, WTD divides the peat column into oxic (air-filled) and anoxic (water-saturated) parts. Anoxic respiration is a source of $\mathrm{CH}_{4}$ and the main part of the anoxic respiration was distributed vertically along an exponential function that describes the vertical distribution of root mass, as root exudates are known to be an important substrate for methanogens (Ström et al., 2003). In contrast to Raivonen et al. (2017), in this study anaerobic decomposition of litter and old peat below water level was also included as a source of $\mathrm{CH}_{4}$. It was modelled with a simple $Q_{10}$ model according to Schuldt et al. (2013).

The model simulates transport of $\mathrm{CH}_{4}, \mathrm{O}_{2}$ and $\mathrm{CO}_{2}$ between peat and the atmosphere by diffusion in air-filled and water-saturated peat and through aerenchymatous wetland plant roots, as well as by ebullition. In case ebullition occurs when WTD is below the peat surface, the ebullition gases are not released directly into the atmosphere but they are transported into the bottom air-filled peat layer. This is called the lowest air layer throughout the study. The plant transport capacity depends on LAI that determines the root mass available for gas transport. Methanotrophy oxidizing $\mathrm{CH}_{4}$ to $\mathrm{CO}_{2}$ is modelled as a dual-substrate Michaelis-Menten process in which both $\mathrm{CH}_{4}$ and $\mathrm{O}_{2}$ concentrations control the oxidation rate. Consequently, the simulated $\mathrm{O}_{2}$ concentrations affect the $\mathrm{CH}_{4}$ loss rate in the peat.

\subsubsection{Ebullition based on concentration threshold (ECT)}

Walter and Heimann (2000) adopted a simple approach to model ebullition: in their approach if the $\mathrm{CH}_{4}$ concentration at a certain depth exceeded a certain threshold concentration, the excess $\mathrm{CH}_{4}$ was directly transported to the air layer above the WTD. In this study we follow Wania et al. (2010) and approximate the threshold pore water $\mathrm{CH}_{4}$ concentration to equal the equilibrium concentration calculated based on Henry's law. Thus, the rate of dissolved $\mathrm{CH}_{4}$ concentration $\left(c_{\mathrm{W}}\right)$ change due to ebullition at a certain depth can be calculated as

$Q_{\mathrm{ebu}}=k\left(c_{\mathrm{w}}-H^{\mathrm{cc}} \frac{p_{\mathrm{tot}}}{R T}\right)$,

where $k$ is ebullition half-life $\left(\frac{\ln (2)}{1800 \mathrm{~s}}\right) ; H^{\mathrm{cc}}$ is the dimensionless Henry solubility of $\mathrm{CH}_{4}$ calculated based on Sander (2015); $p_{\text {tot }}$ is the sum of atmospheric and hydrostatic pressure, i.e. total pressure $(\mathrm{Pa}) ; R$ is the universal gas constant $\left(8.3145 \mathrm{~J} \mathrm{~mol}^{-1} \mathrm{~K}^{-1}\right)$ and $T$ is temperature (K). An equal amount of $\mathrm{CH}_{4}$ that was removed from pore water based on Eq. (2) is immediately released to the lowest air layer, which implies that the bubbles ascend fast enough in order to reach the lowest air layer within the model time step.

\subsubsection{Ebullition based on pressure threshold (EPT)}

Tang et al. (2010) criticized the ECT approach since it uses a $\mathrm{CH}_{4}$ concentration threshold to trigger ebullition, whereas in numerous studies decreasing atmospheric pressure has been shown to lead to bubble release events (Green and Baird, 
Table 1. Parameters needed in the EBG ebullition module. Default values are given, along with different values used in the sensitivity analysis.

\begin{tabular}{|c|c|c|c|c|c|c|c|c|c|c|}
\hline Parameter & Description & $\begin{array}{r}\text { Default } \\
\text { values }\end{array}$ & $\begin{array}{r}\text { Parameter } \\
\text { set } 1.1 \\
\left(f \mathrm{~V}_{\max } \text { low }\right) \\
\end{array}$ & $\begin{array}{r}\text { Parameter } \\
\text { set } 1.2 \\
\left(f \mathrm{~V}_{\max } \text { high }\right)\end{array}$ & $\begin{array}{r}\text { Parameter } \\
\text { set } 2.1 \\
(\chi \text { low })\end{array}$ & $\begin{array}{r}\text { Parameter } \\
\text { set } 2.2 \\
(\chi \text { high })\end{array}$ & $\begin{array}{r}\text { Parameter } \\
\text { set } 3.1 \\
\left(N_{\text {bub }} \text { low }\right)\end{array}$ & $\begin{array}{r}\text { Parameter } \\
\text { set } 3.2 \\
\left(N_{\text {bub }} \text { high }\right)\end{array}$ & $\begin{array}{r}\text { Parameter } \\
\text { set } 4.1 \\
(P \text { low })\end{array}$ & $\begin{array}{r}\text { Parameter } \\
\text { set } 4.2 \\
(P \text { high })\end{array}$ \\
\hline $\begin{array}{l}f_{\mathrm{V}_{\max }} \\
\text { (dimensionless) }\end{array}$ & $\begin{array}{l}\text { Threshold fraction of pore } \\
\text { space filled with gas bub- } \\
\text { bles needed for ebullition }\end{array}$ & 0.1 & 0.05 & 0.15 & 0.1 & 0.1 & 0.1 & 0.1 & 0.1 & 0.1 \\
\hline$\chi\left(\mathrm{mol} \mathrm{mol}^{-1}\right)$ & $\begin{array}{l}\mathrm{CH}_{4} \text { mixing ratio in the } \\
\text { bubbles }\end{array}$ & 0.5 & 0.5 & 0.5 & 0.2 & 0.8 & 0.5 & 0.5 & 0.5 & 0.5 \\
\hline$N_{\text {bub }}($ No.) & $\begin{array}{l}\text { Number of bubbles in one } \\
0.2 \mathrm{~m} \text { thick model layer }\end{array}$ & 100 & 100 & 100 & 100 & 100 & 10 & 1000 & 100 & 100 \\
\hline $\begin{array}{l}P \\
\text { (dimensionless) }\end{array}$ & $\begin{array}{l}\text { Probability that the released } \\
\text { bubble volume will get } \\
\text { trapped at one } 0.2 \mathrm{~m} \text { thick } \\
\text { model layer while it is as- } \\
\text { cending }\end{array}$ & 0.3 & 0.3 & 0.3 & 0.3 & 0.3 & 0.3 & 0.3 & 0 & 0.5 \\
\hline
\end{tabular}

2012; Kellner et al., 2006; Strack et al., 2005; Tokida et al., 2007; Waddington et al., 2009; Yu et al., 2014). Thus, they devised a modelling approach that triggers ebullition at a certain depth if the partial pressures of $\mathrm{CH}_{4}, \mathrm{CO}_{2}, \mathrm{O}_{2}$ and $\mathrm{N}_{2}$ combined exceed the sum of hydrostatic and atmospheric pressure $\left(p_{\text {tot }}\right)$. Tang et al. (2010) also took into account the capillary forces when estimating the pressure threshold; however, in this study these forces were neglected. In HIMMELI partial pressures of $\mathrm{CH}_{4}, \mathrm{CO}_{2}$ and $\mathrm{O}_{2}$ are explicitly calculated using Henry's law and pore water gas concentrations, whereas partial pressure of $\mathrm{N}_{2}$ is assumed constant ( $40 \%$ of atmospheric pressure) throughout the peat column. This value for $\mathrm{N}_{2}$ agrees with empirical evidence, for instance by Tokida et al. (2005) and Walter et al. (2008). The excess moles are then released directly to the lowest air layer, unlike in Tang et al. (2010), who allowed a re-dissolution of bubbles back to water during their ascent. The rate of dissolved $\mathrm{CH}_{4}$ concentration change due to ebullition can then be calculated for each layer as

$Q_{\mathrm{ebu}}=k \frac{f_{\mathrm{ss}} c_{\mathrm{w}}}{H^{\mathrm{cc}}}$,

where $f_{\mathrm{ss}}$ is the relative supersaturation (dimensionless) calculated as

$f_{\mathrm{ss}}=\left\{\begin{array}{c}\frac{p_{\mathrm{tot}}-\sum_{i} p_{i}}{\sum_{i} p_{i}}, \sum_{i} p_{i} \geq p_{\mathrm{tot}} \\ 0, \sum_{i} p_{i}<p_{\mathrm{tot}}\end{array}\right.$,

where $p_{i}$ denotes the partial pressure of $i$ th gas calculated based on Henry's law. The same amount of $\mathrm{CH}_{4}$ that was removed from pore water is then released to the lowest air layer. With this approach ebullition of $\mathrm{CH}_{4}$ may take place even though based on Henry's law water is not supersaturated with $\mathrm{CH}_{4}$. Thus, ebullition may originate from depths with relatively low pore water $\mathrm{CH}_{4}$ concentrations when compared to the ECT approach.

\subsubsection{Ebullition based on bubble growth (EBG)}

Fechner-Levy and Hemond (1996) devised a mathematical framework that describes how temperature, pressure and mass transfer to and from a bubble suspended in water alter the bubble volume. They applied this framework to analyse their peatland data. Later Kellner et al. (2006) applied it to model $\mathrm{CH}_{4}$ ebullition and Zhang et al. (2012) slightly modified the approach and implemented it in a larger processbased model (NEST-DNDC). In this approach bubble volumes are calculated and updated constantly based on the ideal gas law and Henry's law and if bubble volume at a certain depth exceeds a predefined threshold, then the excess volume is released to the atmosphere. This approach is supported by laboratory and field experiments, which have shown that ebullition occurs only if a large enough fraction of the overall pore space volume consists of free-phase gas. This fraction, denoted as $f_{V_{\max }}$ in this study, is commonly reported to be approximately 0.1 .

Initially a bubble volume is formed at a certain depth if $\mathrm{CH}_{4}$ concentration exceeds the concentration that the water can withhold based on Henry's law and assuming that the bubble $\mathrm{CH}_{4}$ mixing ratio $(\chi)$ is fixed at $50 \%$ (see Table 1). The excess $\mathrm{CH}_{4}$ is transferred into a gaseous volume calculated based on the number of excess moles and the predefined bubble $\mathrm{CH}_{4}$ mixing ratio. At each model layer this volume is divided evenly between $N_{\text {bub }}$ spherical bubbles. The bubbles do not have any interaction between each other (no coalescence) and they remain stationary in the peat-water matrix. In principle $N_{\text {bub }}$ is merely a tuning parameter that controls the rate of mass flux between the gas volume and the pore water. Once the bubbles have been formed, the $\mathrm{CH}_{4}$ exchange between the stationary bubbles and the pore water is calculated based on Epstein and Plesset (1950):

$Q_{\mathrm{ebu}}=\frac{4 \pi r D N_{\mathrm{bub}}}{V_{\mathrm{w}}}\left(c_{\mathrm{w}}-\frac{H^{\mathrm{cc}} \chi p_{\mathrm{tot}}}{R T}\right)$, 
where $r$ is the radius of one bubble (m), $D$ is the temperaturedependent effective diffusion coefficient of $\mathrm{CH}_{4}$ in water $\left(\mathrm{m}^{2} \mathrm{~s}^{-1}\right)$ and $V_{\mathrm{w}}$ is the volume of pore water in this model layer $\left(\mathrm{m}^{3}\right)$. $D$ was calculated based on Arah and Stephen (1998) and in order to take into account the fact that the media did not consist solely of water but was a peat-water mixture, the calculated value for $D$ was multiplied with 0.9 prior usage (Raivonen et al., 2017). For simplicity, temperature and pressure inside the bubble volume were assumed to be equal to their pore water counterparts and the mass transfer was assumed to be stationary within the model time step. In order to keep the model in balance, the rate of bubble $\mathrm{CH}_{4}$ $\left(n_{\mathrm{b}}\right.$, unit mol) change at a specific model layer is

$\frac{\partial n_{\mathrm{b}}}{\partial t}=-Q_{\mathrm{ebu}} V_{\mathrm{w}}$

Thus, in this modelling approach $\mathrm{CH}_{4}$ can also be transferred from the bubbles back to the pore water surrounding the bubbles. This kind of feedback is missing from the other ebullition modelling approaches used in this study.

The bubble volume is updated after every model time step based on Eq. (7):

$\Delta V=\frac{\Delta n_{\mathrm{b}}}{c_{\mathrm{b}}}+\frac{\Delta T}{T} V-\frac{\Delta p_{\mathrm{tot}}}{p_{\mathrm{tot}}} V$,

where $V$ is the combined volume $\left(\mathrm{m}^{3}\right)$ of all bubbles at a specific model layer and $c_{\mathrm{b}}$ is the bubble $\mathrm{CH}_{4}$ concentration $\left(\mathrm{mol} \mathrm{m}^{-3}\right)$. The terms on the right-hand side of Eq. (7) represent the change in the volume due to diffusion of $\mathrm{CH}_{4}$ to and from the bubbles (see Eq. 6 above) and change in volume due to temperature or total pressure change. From now on they are called the $c, T$ and $p$ terms, respectively. The $T$ and $p$ terms can be readily calculated from the model input data, whereas the $c$ term can be determined based on Eq. (6).

As stated before, an ebullition event occurs only if bubble volume at a certain depth exceeds a predefined threshold $\left(V_{\max }\right)$ :

$F_{\text {ebu }}=\left\{\begin{array}{c}0, V+\Delta V \leq V_{\max } \\ c_{\mathrm{b}} \frac{V+\Delta V-V_{\max }}{\Delta t}, V+\Delta V>V_{\max }\end{array}\right.$,

where $F_{\text {ebu }}$ is the ebullition flux of $\mathrm{CH}_{4}$ to the lowest air layer $\left(\mathrm{mol} \mathrm{s}^{-1}\right), V_{\max }$ can be calculated as a product of $V_{\mathrm{w}}$ and $f_{V \max }$, and $\Delta t$ is the model time step. Finally, the updated bubble volume at a certain depth is

$V=\left\{\begin{array}{c}V+\Delta V, V+\Delta V \leq V_{\max } \\ V_{\max }, V+\Delta V>V_{\max }\end{array}\right.$,

and the number of $\mathrm{CH}_{4}$ moles in the bubbles at a certain model layer after each model time step is

$n_{\mathrm{b}}=\frac{\chi p_{\text {tot }} V}{R T}$.
In order to take into account bubble movement in the peat column after it has been released (i.e. $V+\Delta V>V_{\max }$ ), a simple approach was adopted: excess bubble volumes are released starting from the bottom of the peat column and while the gaseous volume is ascending it will get trapped at a certain $0.2 \mathrm{~m}$ thick model layer with a probability of $P$, which was set to 0.3 . Thus, for instance, a bubble released from $1 \mathrm{~m}$ below the lowest air layer will reach the air layer with a probability of $0.17\left((1-0.3)^{5} \approx 0.17\right)$. Otherwise it will stay at the depth where it got trapped and its volume will be updated during the next time step with the procedure described above. This process is repeated for each layer where $V+\Delta V>V_{\max }$ and thus at the end of the time step bubble volumes are always smaller than or equal to $V_{\max }$. This kind of approach produces somewhat similar bubble movement as the "inverted bubble avalanches" modelled with the approach suggested by Coulthard et al. (2009) and used by Ramirez et al. (2015). By setting the probability $P$ to 0 the released excess bubble volume will always reach the lowest air layer, similar to the other ebullition modelling approaches included in this study. The performance of the EBG approach using different values for $P$ and other parameters is evaluated in Sect. 3.4.

The effect of changing water table level was taken into account in the following way: if the water table dropped below a layer that contained bubbles, the $\mathrm{CH}_{4}$ in the bubbles was immediately released to the newly formed air-filled pore space. If the water table rose, the new water-clogged pore space did not initially contain any bubbles.

\subsection{Site and measurements}

The measurements were carried out at an oligotrophic open fen part of the Siikaneva wetland complex that is situated in the southern part of Finland $\left(61^{\circ} 50^{\prime} \mathrm{N}, 24^{\circ} 12^{\prime} \mathrm{E}\right.$, $162 \mathrm{~m}$ a.s.l.). The site is in the boreal region with an annual average temperature of $3.3^{\circ} \mathrm{C}$ and rainfall of $710 \mathrm{~mm}$ (Drebs et al., 2002). The vegetation composition is dominated by sedges (C. rostrata, C. limosa, E. vaginatum), Rannochrush (Scheuchzeria palustris) and peat mosses (Sphagnum balticum, S. majus, S. papillosum). Peat depth at the site varies between 2 and $4 \mathrm{~m}$. See more details in Riutta et al. (2007) and Rinne et al. (2007).

The HIMMELI model was driven using measured peat temperature, atmospheric pressure, WTD, simulated LAI and anoxic respiration. See the details about LAI and anoxic respiration simulation in Raivonen et al. (2017) and Susiluoto et al. (2017). Peat temperature was measured at five depths below the surface $(-5,-10,-20,-35$ and $-50 \mathrm{~cm})$ and the measurements were interpolated linearly in time and space in order to match every model time step and depth. Temperatures below $-50 \mathrm{~cm}$ were obtained by assuming that at $3 \mathrm{~m}$ the peat temperature is constant $\left(7^{\circ} \mathrm{C}\right.$, average temperature at $-50 \mathrm{~cm}$ ). WTD and atmospheric pressure time series were also gap-filled using linear interpolation. Air pressure was 
not measured at the site and hence measurements made $5 \mathrm{~km}$ away at the SMEAR II (Hari and Kulmala, 2005) site were used.

In this study the modelled daily $\mathrm{CH}_{4}$ fluxes are compared with fluxes obtained with the eddy covariance (EC) method at the Siikaneva site. Data from 2008 to 2011 are used. EC measurements estimate the ecosystem-scale emissions of measured compounds $\left(\mathrm{CH}_{4}\right.$ in this study) and hence the measured fluxes integrate all three $\mathrm{CH}_{4}$ emission pathways (plant transport, diffusion and ebullition) on the ecosystem scale. The EC set-up consisted of a sonic anemometer (USA-1, Metek GmbH) that measured the three wind components and air temperature and a fast-response gas analyser used to measure $\mathrm{CH}_{4}$. The instruments measured the turbulent fluctuations $2.75 \mathrm{~m}$ above the peat surface. There were some changes in the $\mathrm{CH}_{4}$ instrumentation during the years. The $\mathrm{CH}_{4}$ analysers used were a RMT-200 from Los Gatos Research (2008-2011), TGA100 from Campbell Scientific (04/2010-08/2010) and G1301-f from Picarro (04/201010/2011). The gas analysers were located in a separate housing that protected the instruments from the outdoor conditions. A sampling line consisting of filters and heated Teflon tubing was used to sample air to the closed-path gas analysers. See more details in Peltola et al. (2013).

The EC measurements were made at $10 \mathrm{~Hz}$, from which the fluxes were calculated as a covariance between vertical wind and gas concentration using $30 \mathrm{~min}$ averaging time. Coordinates were rotated with sector-wise planar fitting, and high-frequency losses were corrected using empirical procedures (see Peltola et al., 2013). All EC data post-processing steps were performed using EddyUH (Mammarella et al., 2016). The EC data were carefully processed keeping in mind the nature of the ebullition process (rapid-release events with significantly elevated concentrations), and processing steps such as de-spiking were tuned so that these events were not flagged as erroneous measurements.

\section{Results}

\subsection{Timing and depth of ebullition events}

The EPT approach resulted in the highest total number of ebullition events (866 events), followed by EBG (797) and ECT (389) (Fig. 1). An ebullition event is defined as a time period and depth at which the concentration (ECT approach), pressure (EPT) or volume (EBG) threshold was exceeded (see Sect. 2). As stated in Sect. 2.2, the EPT approach does not require that the pore water $\mathrm{CH}_{4}$ concentration reaches supersaturation; it uses the total pressure of water-dissolved gases to trigger an ebullition event, which is a less strict requirement for ebullition. Hence a higher number of events were observed with the EPT approach. The ECT approach requires high pore water $\mathrm{CH}_{4}$ concentrations in order to trigger an ebullition event, which limits the number of ebulli- tion events, whereas EBG may trigger an ebullition event due to four reasons: increased $\mathrm{CH}_{4}$ concentration in pore water ( $c$ term of Eq. 7), increased temperature ( $T$ term of Eq. 7), decreased WTD or atmospheric pressure ( $p$ term of Eq. 7).

Most of the events took place in July. For the ECT, EPT and EBG approaches 43, 35 and $36 \%$ of all events happened during that particular month, respectively (Fig. 1). The vertical distributions of the ebullition events in Fig. 1 show that for the EBG and EPT approaches the events usually originated from below $1 \mathrm{~m}$ depth and for ECT below $1.4 \mathrm{~m}$ depth. For EBG this means that below $1 \mathrm{~m}$ depth the conditions were favourable for bubble volume increase, which led the volume to exceed the maximum volume allowed $\left(V_{\max }\right)$ and hence to trigger an ebullition event. In order to sustain and grow bubbles with the EBG approach, relatively high pore water $\mathrm{CH}_{4}$ concentrations are needed (see Eq. 5) and thus the ebullition events originated from depths below rooting depths and layers with oxic pore water (Fig. 1d). For the same reason, the ECT approach resulted in ebullition events only from the deep pore water. $\mathrm{CH}_{4}$ in the pore water below rooting depth resulted mostly from decay of old peat since root exudates were not present and if this source of $\mathrm{CH}_{4}$ was omitted in the model, all the approaches stopped producing ebullition events altogether.

Less than half ( $41 \%$ ) of the ebullition events triggered by the EBG approach coincided with a co-located event triggered by the ECT approach, whereas $78 \%$ of the events took place at the same depth and time as the EPT approach. Most (70 and $78 \%$, respectively) of the events happened at the same time as the events modelled with the ECT and EPT approaches regardless of depth. Conversely, $72 \%$ of the events triggered with the EPT approach matched EBG events, while they matched only $43 \%$ of the ECT events. Hence EPT and EBG triggered ebullition events mostly at the same time and location; however, ECT differed more from the other two approaches.

Decreasing WTD (i.e. decreasing hydrostatic pressure) and air pressure triggered approximately 66 and $67 \%$ of ebullition events when using the EPT approach, respectively. Almost all $(94 \%)$ of the ebullition events observed with the EPT approach coincided with either decreasing WTD or decreasing atmospheric pressure; the other $6 \%$ were triggered solely by increasing partial pressures, i.e. increase in $\mathrm{CH}_{4}$, $\mathrm{CO}_{2}$ or $\mathrm{O}_{2}$ pore water concentrations (see Sect. 2.2). For the EBG approach a large proportion of the events were triggered simultaneously due to all the three terms, namely the $c, p$ and the $T$ terms (47\%). Only $1 \%$ of the events were caused solely by decreasing total pressure, i.e. the $p$ term. Individually examined, almost all of the events took place due to the $c$ term $(99 \%)$ or the $p$ term of Eq. (7) $(86 \%)$, whereas the $T$ term had a slightly smaller impact (57\% of all events). Most (72\%) of the ebullition events triggered by the $p$ term coincided with decreasing atmospheric pressure and $59 \%$ with decreasing WTD. 


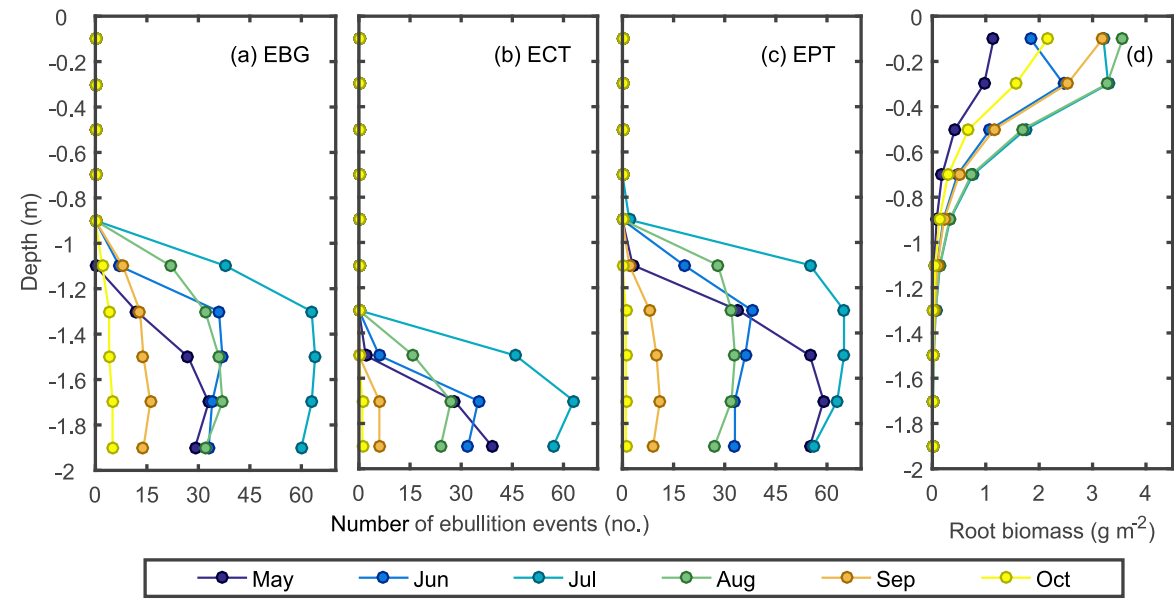

Figure 1. Number of ebullition events at different months and depths (a-c) and distribution of plant roots under the water table (d). During other months (November-April) only $1 \%$ of all ebullition events took place and thus data from those months are not shown.

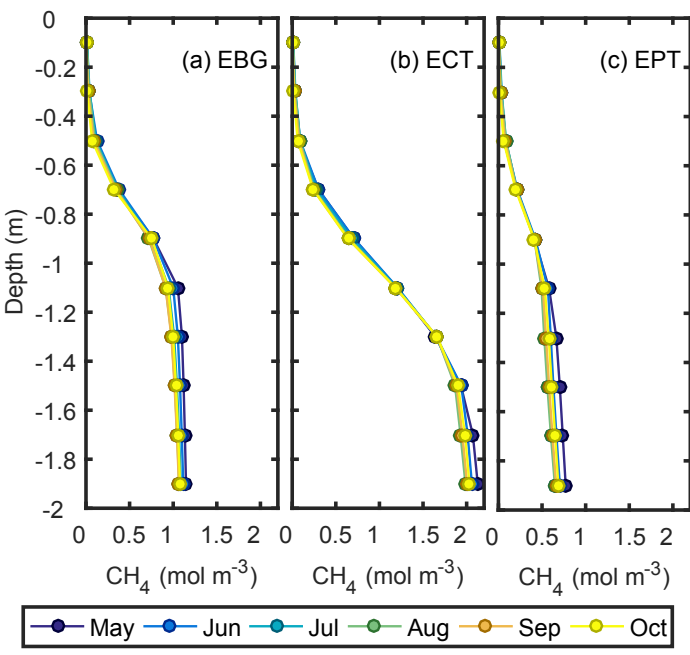

Figure 2. Average $\mathrm{CH}_{4}$ pore water concentrations at different depths and months.

\section{2 $\mathrm{CH}_{4}$ and bubble volume profiles and dynamics}

EPT approach showed the lowest pore water $\mathrm{CH}_{4}$ concentrations $\left(0.39 \mathrm{~mol} \mathrm{~m}^{-3}\right)$. EBG and ECT calculated on average 1.7 and 2.5 times higher values $\left(0.66\right.$ and $0.98 \mathrm{~mol} \mathrm{~m}^{-3}$, respectively) and the difference was emphasized at the deepest layers (see Fig. 2). If the concentrations were converted to gaseous-phase partial pressures using Henry's law and scaled with the total pressure $\left(p_{\mathrm{CH}_{4}} / p_{\text {tot }}\right)$, the reason for the differences could be found. With the EBG approach the diffusive mass transfer between the bubbles and the pore water was directed from the water to the bubbles if $p_{\mathrm{CH}_{4}} / p_{\text {tot }}$ exceeded the predefined bubble $\mathrm{CH}_{4}$ mixing ratio $\chi$, which was set to $50 \%$ in this study. Conversely, the $\mathrm{CH}_{4}$ flux was directed from the bubbles to the pore water if the ratio was smaller

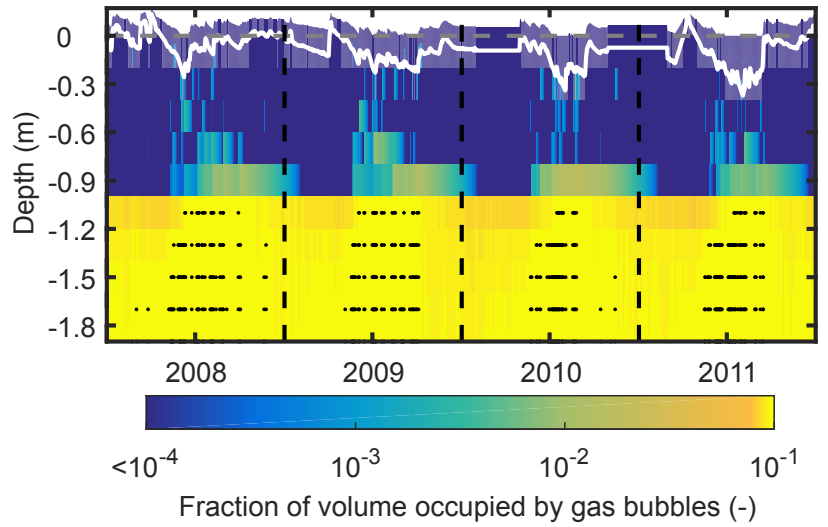

Figure 3. Bubble volume profiles calculated with the EBG approach. Black dots highlight periods and depths with ebullition events. The white line shows the water table depth.

than $\chi$. This follows directly from Eq. (5), more specifically from the difference between $c_{\mathrm{W}}$ and the equilibrium concentration $\left(\frac{H^{\mathrm{cc}} \chi p_{\text {tot }}}{R T}\right)$. Hence, the $\mathrm{CH}_{4}$ concentrations rose until $p_{\mathrm{CH}_{4}} / p_{\text {tot }}$ exceeded $\chi$, after which part of the $\mathrm{CH}_{4}$ produced went into the bubbles instead of staying in the pore water, which limited the increase in the $\mathrm{CH}_{4}$ pore water concentrations. If the effect of surface tension would have been included in the pressure inside the bubbles, higher $p_{\mathrm{CH}_{4}} / p_{\text {tot }}$ values would have been needed (i.e. higher pore water $\mathrm{CH}_{4}$ concentrations) to transfer $\mathrm{CH}_{4}$ from the pore water to the bubbles. The build-up of pore water $\mathrm{CH}_{4}$ concentrations took place only below $1 \mathrm{~m}$ depth since closer to the surface the plant roots effectively removed $\mathrm{CH}_{4}$ from the pore water via aerenchyma (compare Figs. 1d and 2). For the ECT approach the pore water $\mathrm{CH}_{4}$ concentrations increased until $p_{\mathrm{CH}_{4}} / p_{\text {tot }}$ equalled unity (i.e. supersaturation of $\mathrm{CH}_{4}$ in pore water), after which the excess $\mathrm{CH}_{4}$ was removed in ebullition events. 


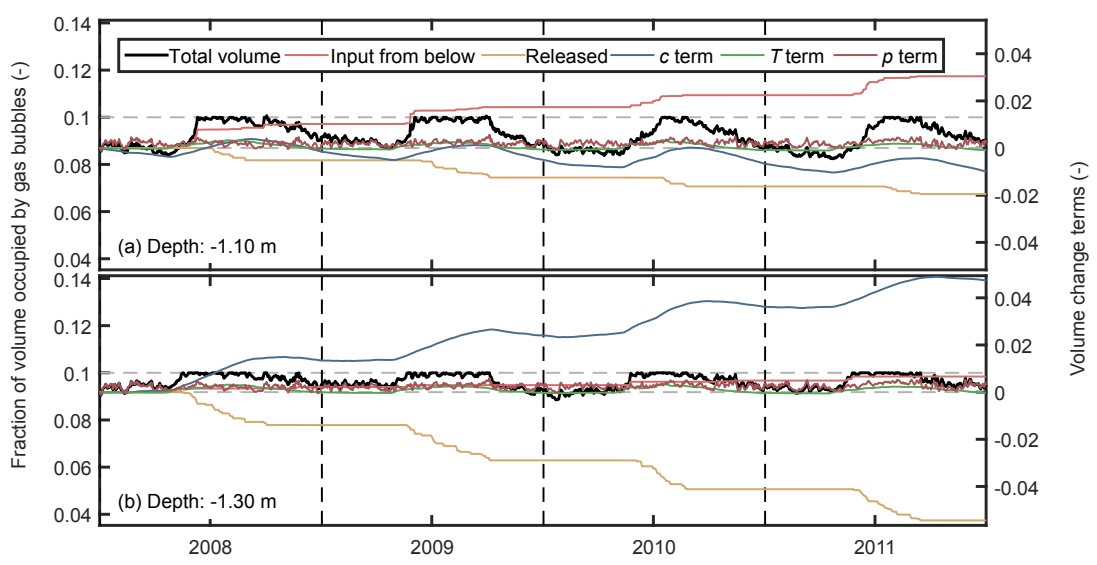

Figure 4. Fraction of volume occupied by gas bubbles at two example depths calculated with the EBG approach. Black lines show the modelled volume (left $y$ axis) and the other continuous lines (right $y$ axis) show the terms causing the volume changes. Therefore, the sum of the lines in colour yield the changes in the black line at every time step. The light grey dashed line highlights the volume threshold $\left(f_{V_{\max }}=0.1\right)$, after which additional volume increase was released in an ebullition event.

This implies that with the ECT approach the bubbles consist of $100 \%$ of $\mathrm{CH}_{4}$. Conversely, for the EPT approach the increase in pore water $\mathrm{CH}_{4}$ concentrations was limited by the fact that the sum of $\mathrm{CH}_{4}, \mathrm{CO}_{2}, \mathrm{~N}_{2}$ and $\mathrm{O}_{2}$ partial pressures was allowed to be at maximum $p_{\text {tot }}$ and since $p_{\mathrm{O}_{2}}$ values were low and $p_{\mathrm{N}_{2}}$ was $40 \%$ of the atmospheric pressure throughout the peat column, then the sum of $p_{\mathrm{CO}_{2}}$ and $p_{\mathrm{CH}_{4}}$ below the rooting depth could be around $50-65 \%$ of $p_{\text {tot }}$, depending on depth. Hence the low pore water $\mathrm{CH}_{4}$ concentrations in Fig. 2c. $p_{\mathrm{CH}_{4}} / p_{\text {tot }}$ (i.e. the bubble $\mathrm{CH}_{4}$ mixing ratio) during ebullition events with the EPT approach was generally between 25 and $38 \%$, whereas $p_{\mathrm{CO}_{2}} / p_{\text {tot }}$ (i.e. the bubble $\mathrm{CO}_{2}$ mixing ratio) was between 28 and $37 \%$.

Bubble volumes modelled with the EBG approach mostly resided below $1 \mathrm{~m}$ depth (Fig. 3) where the conditions were favourable for bubble growth. Bubble volumes were affected by three terms: $\mathrm{CH}_{4}$ transfer between the bubbles and pore water ( $c$ term) and expansion-contraction due to temperature ( $T$ term) or pressure changes ( $p$ term). Input of gaseous volume released from deeper layers also increased the bubble volumes, whereas bubble release limited the volume to be at maximum $V_{\max }$ (Fig. 4).

The $c$ term showed clear seasonality (decreasing bubble volumes during late summer and autumn and increasing volumes in spring and early summer) since it was closely related to temperature (see Eq. 5): $\mathrm{CH}_{4}$ solubility decreases with temperature (i.e. $H^{\mathrm{cc}}$ decreases) and due to enhanced $\mathrm{CH}_{4}$ production, pore water $\mathrm{CH}_{4}$ concentrations $\left(c_{\mathrm{W}}\right)$ increase with temperature. Bubble volumes released from deeper layers and that were reattached during their ascent maintained the gas volume at $-1.1 \mathrm{~m}$ depth even though the $c$ term on average decreased the volume (see Fig. 4a).

The $T$ and $p$ terms generated only temporal variation in the volumes without any permanent increase or decrease. The $T$ term generated seasonality to the bubble volumes, al- though the seasonality was mostly controlled by the $c$ term. The $p$ term caused strong short-term variation and a small seasonal cycle due to the annual cycle of WTD. Altogether the combination of all these terms, in addition to the input and release of gaseous volume, led the bubble volumes to reach their maxima in July and minima in April and generated the ebullition event profile and seasonality shown in Fig. 1a.

\section{3 $\mathrm{CH}_{4}$ emissions to the atmosphere}

The EPT approach resulted in significantly higher temporal variability in the $\mathrm{CH}_{4}$ emission to the atmosphere than the other ebullition modelling approaches (Fig. 5) due to the fact that it produced more ebullition events, which caused the short-term variability in the $\mathrm{CH}_{4}$ emissions. In order to quantify the short-term variability, the amount of variance in the time series at high frequencies was estimated by calculating the time series' power spectral densities and integrating them over the frequency range of interest. Variability on a timescale shorter than 1 week contributed approximately 24 , 12 and $7 \%$ to the total time series variance obtained with the EPT, ECT and EBG approaches, respectively, whereas for the measured $\mathrm{CH}_{4}$ flux time series the contribution was $3 \%$ to the total variance. There were also differences in the total time series variance: EPT and ECT gave 92 and $17 \%$ higher variances for the $\mathrm{CH}_{4}$ flux time series than the measurements, whereas EBG estimated $13 \%$ lower variance for the $\mathrm{CH}_{4}$ emission time series. These results can be qualitatively observed in Fig. 5: the EPT approach clearly showed the highest variability, especially on short timescales, followed by ECT and finally EBG and the measured $\mathrm{CH}_{4}$ flux time series. The EBG approach explained the variability in the measured $\mathrm{CH}_{4}$ emissions the best ( $R^{2}$ was 0.63 ), followed by ECT (0.56) and EPT (0.35). These results are consistent with 


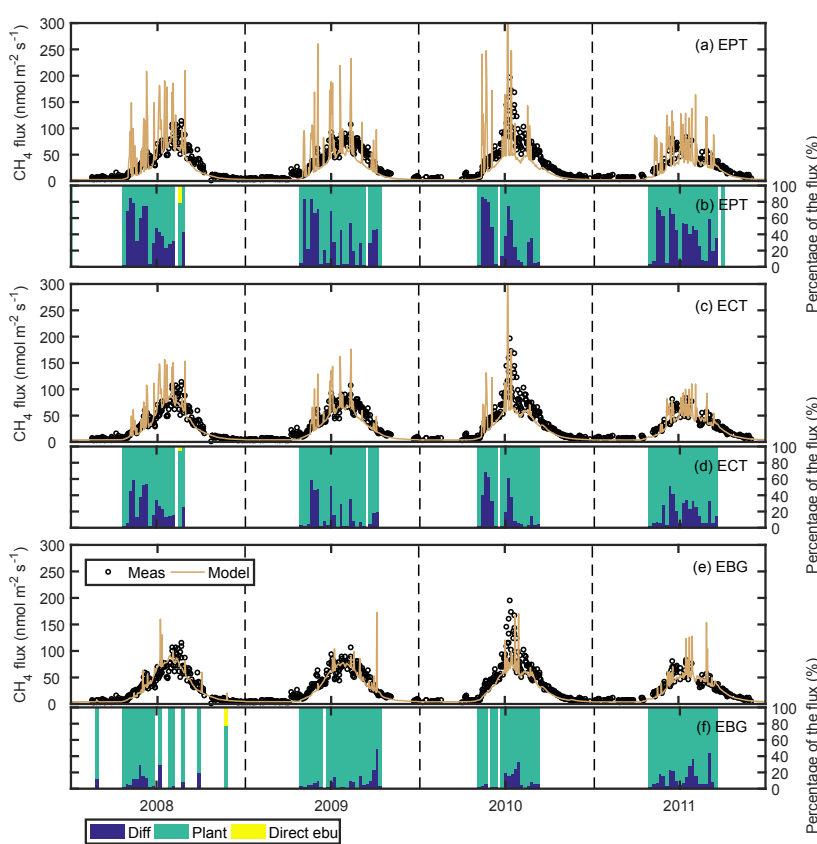

Figure 5. Daily $\mathrm{CH}_{4}$ fluxes from the fen to the atmosphere obtained using different approaches for modelling ebullition (a, $\mathbf{c}$ and $\mathbf{e}$ ) and weekly contribution of three emission pathways to flux (b, $\mathbf{d}$ and f). The legend for panels (b), (d) and (f) is located at the bottom of the figure. Measured fluxes are shown with circles; diff: diffusion; plant: plant transport; direct ebu: ebullition directly to the surface. The diffusion flux contains the ebullition flux released to the lowest air layer, which is usually below the peat surface. White areas in panels (b), (d) and (f) correspond to periods when over $99 \%$ of the flux was related to the plant-mediated transport.

the differences in time series variance outlined above. However, the model results represent $\mathrm{CH}_{4}$ exchange from a single horizontally homogeneous peat column, whereas the measured fluxes correspond to ecosystem-scale $\mathrm{CH}_{4}$ exchange. Hence they are not fully comparable with each other.

Even though the $\mathrm{CH}_{4}$ flux time series variances were affected by the ebullition modelling approach, the annual net $\mathrm{CH}_{4}$ emissions were not largely different between the three modelling approaches (Table 2). At maximum the modelling approaches diverged by $1.0 \mathrm{~g}\left(\mathrm{CH}_{4}\right) \mathrm{m}^{-2} \mathrm{yr}^{-1}$ in $2008(7 \%$ of the annual emission). In general all the approaches showed a similar decreasing trend from 2008 to 2010 in the annual $\mathrm{CH}_{4}$ emissions and none of them always showed the lowest or highest emissions. Similar annual $\mathrm{CH}_{4}$ emissions could have been expected given the fact that ebullition does not directly alter the $\mathrm{CH}_{4}$ production and hence it only provides another transport pathway for emissions, which would happen on annual timescale regardless of the transport route, although $\mathrm{CH}_{4}$ oxidation in the peat column might be different between the modelling approaches.

The relative magnitude of different emission pathways varied between the modelling approaches (Fig. 5b, $d$ and $f$ and Table 2). On an annual scale for the EBG approach the $\mathrm{CH}_{4}$ emissions via plant aerenchyma contributed approximately 90 and diffusion $10 \%$ of the total $\mathrm{CH}_{4}$ emissions. For ECT the percentages were 80 and $20 \%$ and for EPT 60 and $40 \%$, respectively. In HIMMELI the ebullition flux is released to the lowest air layer, which is often below peat surface and hence the diffusion flux to the atmosphere also contains the ebullition flux signal. Due to the same reason, the direct ebullition to the surface is rare (Fig. 5) since ebullition events usually take place when WTD is below surface and thus ebullition flux is not released directly to the atmosphere. The ebullition flux to the lowest air layer was 4 to 9 times higher in the EPT approach than in the EBG approach and also approximately double that calculated with the ECT approach (Table 2), which was related to the overall higher number of ebullition events modelled by the EPT approach (see Sect. 3.1). In addition, when using the EBG approach many of the ebullition events were trapped during their ascent and then dissolved back to the pore water and thus they did not reach the lowest air layer and contribute to the ebullition flux.

\subsection{Testing the EBG approach with different model parameter values}

The EBG approach was tested with different parameter values (see Table 1) in order to evaluate the sensitivity of the results to the used parameters. This analysis revealed that the EBG approach was the most sensitive to the bubble $\mathrm{CH}_{4}$ mixing ratio. If the mixing ratio was set to $20 \%$ (parameter set 2.1) instead of the $50 \%$ used in the default run, 2164 events were triggered with the EBG approach, which is approximately 3 times the number observed with the default run (see Fig. 6b). Consequently, more $\mathrm{CH}_{4}$ was transported to the lowest air layer via ebullition (annual mean: $1.2 \mathrm{~g}\left(\mathrm{CH}_{4}\right) \mathrm{m}^{-2} \mathrm{yr}^{-1}$, with default run: $0.7 \mathrm{~g}\left(\mathrm{CH}_{4}\right) \mathrm{m}^{-2} \mathrm{yr}^{-1}$; Fig. 6d) and hence a slightly larger fraction of $\mathrm{CH}_{4}$ was emitted to the atmosphere via diffusion (14\%, Fig. 6e). However, the total amount of emitted $\mathrm{CH}_{4}$ to the atmosphere was approximately $5 \%$ lower (Fig. 6c), possibly due to the fact that the large number of ebullition events transported $\mathrm{CH}_{4}$ to upper oxic peat layers where the $\mathrm{CH}_{4}$ was oxidized rather than released to the atmosphere. Also, bubbles were formed closer to the surface than in the EBG default run (see Fig. 3 for the default run). These results were reasonable given the fact that the lower mixing ratio facilitated the $\mathrm{CH}_{4}$ transfer from the pore water to the bubbles and hence the bubble growth. Conversely, a higher bubble $\mathrm{CH}_{4}$ mixing ratio (parameter set 2.2) decreased the number of ebullition events to 394 (50\% decrease) and limited the bubble formation to depths below $1.2 \mathrm{~m}$, which was deeper than in the default run (Fig. 3).

The variance in the modelled $\mathrm{CH}_{4}$ flux to the atmosphere was the most sensitive to the parameter (probability $P$ ) controlling the bubble movement in the peat column (Fig. 6a). 


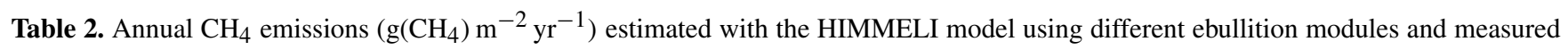
with eddy covariance. Values in parentheses show the relative contribution (\%) of each $\mathrm{CH}_{4}$ emission pathway to the total annual emission estimate.

\begin{tabular}{|c|c|c|c|c|c|}
\hline & & EBG & ECT & EPT & Measured \\
\hline \multirow{5}{*}{2008} & Total & 12.9 & 13.7 & 13.9 & 11.9 \\
\hline & Plant transport & $12.2(94)$ & $11.3(82)$ & $9.0(65)$ & \\
\hline & Diffusion & $0.7(6)$ & $2.4(18)$ & $4.7(34)$ & \\
\hline & Ebullition & $0(0)$ & $0(0)$ & $0.1(1)$ & \\
\hline & $\begin{array}{l}\text { Ebullition to the lowest } \\
\text { air-filled pore space* }\end{array}$ & 0.5 & 2.4 & 4.8 & \\
\hline \multirow{5}{*}{2009} & Total & 12.4 & 12.3 & 12.6 & 12.8 \\
\hline & Plant transport & $11.5(93)$ & $10.2(83)$ & $8.0(63)$ & \\
\hline & Diffusion & $0.8(7)$ & $2.1(17)$ & $4.6(37)$ & \\
\hline & Ebullition & $0(0)$ & $0(0)$ & $0(0)$ & \\
\hline & $\begin{array}{l}\text { Ebullition to the lowest } \\
\text { air-filled pore space* }\end{array}$ & 0.6 & 1.9 & 4.5 & \\
\hline \multirow{5}{*}{2010} & Total & 11.6 & 12.4 & 12.4 & 14.7 \\
\hline & Plant transport & $10.6(91)$ & $9.9(80)$ & $7.6(61)$ & \\
\hline & Diffusion & $1.0(9)$ & $2.5(20)$ & $4.8(39)$ & \\
\hline & Ebullition & $0(0)$ & $0(0)$ & $0(0)$ & \\
\hline & $\begin{array}{l}\text { Ebullition to the lowest } \\
\text { air-filled pore space* }\end{array}$ & 0.7 & 2.3 & 4.7 & \\
\hline \multirow{5}{*}{2011} & Total & 10.8 & 10.7 & 10.7 & 11.6 \\
\hline & Plant transport & $9.5(87)$ & $8.8(82)$ & $6.6(61)$ & \\
\hline & Diffusion & $1.4(13)$ & $2.0(18)$ & $4.2(39)$ & \\
\hline & Ebullition & $0(0)$ & $0(0)$ & $0(0)$ & \\
\hline & $\begin{array}{l}\text { Ebullition to the lowest } \\
\text { air-filled pore space* }\end{array}$ & 1.0 & 1.7 & 4.0 & \\
\hline
\end{tabular}

* Not included in the total annual $\mathrm{CH}_{4}$ emission.

If the probability at which the released bubble volume becomes trapped while it was ascending was increased from the default value (parameter set 4.2; see Table 1), the flux time series variance was slightly decreased. If the probability was set to 0 (parameter set 4.1), the EBG results resembled results obtained with the ECT approach since the ebullition flux was more directly linked with bubble production, which was in turn driven by changes in $\mathrm{CH}_{4}$ pore water concentration (see Fig. 4). Ebullition flux to the lowest air layer was approximately 3 times higher (Fig. 6d) since all the ebullition events reached the layer and were not trapped during their ascent. This also lead the diffusion pathway to have a higher fraction of the overall emission of $\mathrm{CH}_{4}$ to the atmosphere ( $28 \mathrm{vs.} 8 \%$ with the default run; Fig. 6e).

If the threshold fraction for gaseous volume $\left(f_{V_{\max }}\right)$ was decreased to $5 \%$ (parameter set 1.1; see Table 1), the number of ebullition events was increased by $59 \%$ (1268 events observed) since smaller bubble volumes were needed before an ebullition event was triggered. A larger value for $f_{V_{\max }}$ (parameter set 1.2) decreased the number of ebullition events by $26 \%$ (Fig. 6b). Otherwise changing the value for $f_{V_{\max }}$ had a negligible impact on the model results. Increasing or decreasing the number of bubbles in a model layer $\left(N_{\text {bub }}\right)$ accelerated or decelerated the $\mathrm{CH}_{4}$ transfer between the bubbles and pore water (see $c$ term in Eq. 4), but on the whole it had a minimal effect on the modelled ebullition (see the results for parameter sets 3.1 and 3.2 in Fig. 6).

\section{Discussion}

All of the modelling approaches produced ebullition events only deep below the surface. Hence the results resemble the "deep peat" hypothesis put forward by Glaser et al. (2004) in which the free-phase gas is produced in deep $(>1 \mathrm{~m})$ peat and trapped under semi-confined layers, even though peat micro structure (e.g. woody layers) was not described in the model. According to the hypothesis, these layers episodically rupture due to changes in gas volume buoyancy inflicted by, for instance, pressure changes. Hence it links ebullition mostly to the processes that take place in the deep peat and it has 


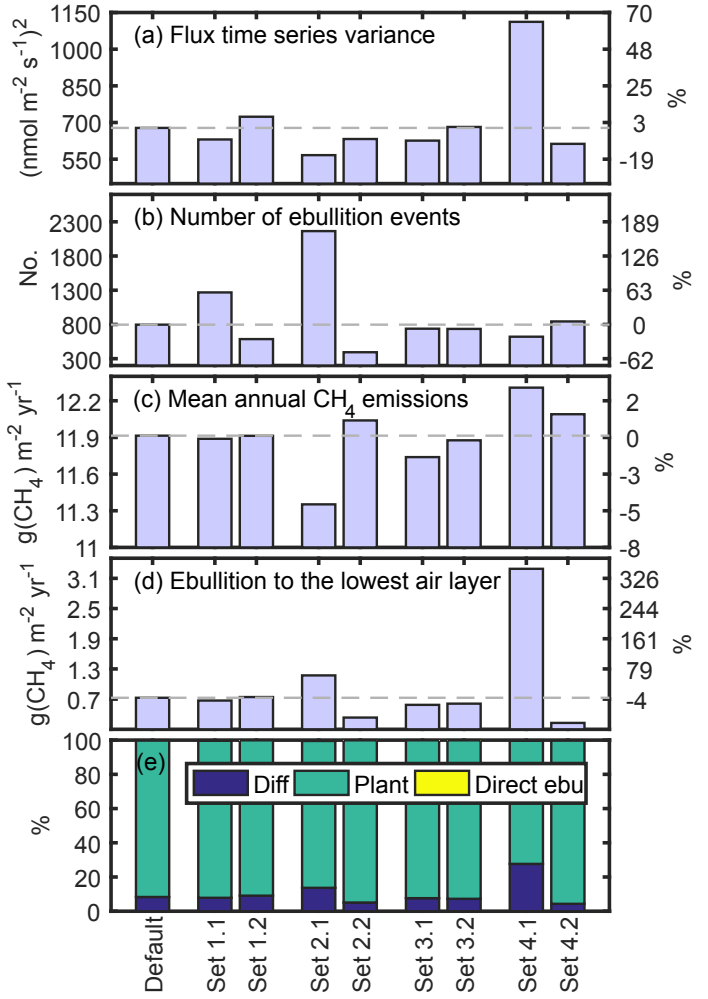

Figure 6. Results from the EBG sensitivity analysis (see parameter values in Table 1): variance in the $\mathrm{CH}_{4}$ flux time series (a), total number of ebullition events (b), mean annual $\mathrm{CH}_{4}$ emissions (c), mean annual ebullition flux to the lowest air layer (d) and the average contribution of different emission pathways to the overall $\mathrm{CH}_{4}$ flux to the atmosphere (e). Direct ebullition to the surface is negligible on an annual scale and hence not visible in panel (e). Absolute values are on the $y$ axis on the left, and change relative to the default run is on the right side. Grey dashed lines highlight the values obtained with the default run.

been supported by some field studies. For instance, in a relatively recent study, Bon et al. (2014) observed high $\mathrm{CH}_{4}$ pore water concentrations below $2 \mathrm{~m}$ depth, which they claim to be an indication of free-phase gas and hence ebullition from the deep peat.

There is, however, mounting evidence that bubble formation and release also takes place close to the surface, which is in contrast to the deep peat hypothesis. Hence, Coulthard et al. (2009) argued that the bubble formation and ebullition is more directly linked with processes that take place close to the surface, primarily because most of the labile fresh carbon is located in the rooting zone and hence $\mathrm{CH}_{4}$ production is higher in the shallow peat than deeper below the surface. The "shallow peat" hypothesis was supported, for instance, by Klapstein et al. (2014), who showed in their field study that over $90 \%$ of ebullition occurred in the surface peat layer and the carbon in the bubble $\mathrm{CH}_{4}$ was recently fixed from the atmosphere. As mentioned before, for the EBG modelling approach pore water $\mathrm{CH}_{4}$ concentrations need to be high enough (above $\frac{H^{\mathrm{cc}} \chi p_{\text {tot }}}{R T}$ ) to form and grow a bubble at a certain model layer. This sets a strict limit for where bubbles may exist and the presence of vascular plants' roots effectively prevented bubble formation close to the surface by limiting the pore water $\mathrm{CH}_{4}$ concentrations. Thus, there is clearly a conflict between the shallow peat hypothesis and the EBG modelling approach. It could be slightly alleviated by lowering the bubble $\mathrm{CH}_{4}$ mixing ratio $(\chi)$, which would allow bubbles to exist at lower pore water $\mathrm{CH}_{4}$ concentrations, or by using a predefined profile for $\chi$ (increase with depth), instead of one constant fixed value. In general the reported bubble $\mathrm{CH}_{4}$ mixing ratios are at minimum $10 \%$, which equals $\mathrm{CH}_{4}$ pore water concentration of $0.15 \mathrm{~mol} \mathrm{~m}^{-3}$ (based on Henry's law at $T=15^{\circ} \mathrm{C}$ and $p_{\text {tot }}=1013 \mathrm{hPa}$ ). However, for instance, Baird et al. (2004) have shown bubble build-up initiation at approximately 5times-lower average $\mathrm{CH}_{4}$ pore water concentrations. This could be explained by strong small-scale variability in pore water $\mathrm{CH}_{4}$ concentration, which is undetectable with the current measurement methods and hence by the methods used by Baird et al. (2004). Such variability could create small pockets of high $\mathrm{CH}_{4}$ concentrations where bubble formation and growth could take place. That kind of variability cannot, however, be readily implemented in 1-D column models and alternate ways of dealing with this issue should be developed.

It is also possible that the vascular plants in reality did hinder bubble formation and growth at the study site, deeming the EBG results plausible. However, this cannot be confirmed since free-phase gas content was not measured at the site. Coulthard et al. (2009) claim that vascular plants do not necessarily inhibit ebullition from shallow peat due to their strong influence on $\mathrm{CH}_{4}$ production, whereas Chanton (2005) suggest the opposite. The empirical studies are also not conclusive in this matter. For instance, Klapstein et al. (2014) did not observe any negative effect of sedge cover on ebullition, whereas Green and Baird (2012) showed that the percentage of $\mathrm{CH}_{4}$ emitted in episodic ebullition events decreased with the presence of sedges. Green and Baird (2012) conclude that the sedge effects on $\mathrm{CH}_{4}$ emissions via ebullition may be species dependent. Clearly the effect of sedges on ebullition should be studied more prior to these effects being implemented in terrestrial $\mathrm{CH}_{4}$ models.

While the bubble movement was implemented in the EBG approach in a relatively simple way, note that in most of the modelling studies it has been ignored completely. Ramirez et al. (2016) showed that the peat pore structure had a significant influence on the bubble size distribution and release, and their results suggest that peat structure might be more important than production rate in controlling ebullition. Hence emphasis on future ebullition modelling should be on describing the bubble movement in a simplistic yet accurate way. The reduced complexity model MEGA developed by Ramirez et al. (2015) is a step in the right direction in this respect. In the EBG approach used in this study the effect of peat pore structure on bubble movement can be controlled by modify- 
ing the probability at which bubbles adhere at certain levels while they ascent $(P)$ and by changing the volume threshold $\left(V_{\max }\right)$ after which the bubbles are released. A profile for both of these parameters would allow taking into account the vertical variation in peat pore structure and its effect on bubble mobility and accumulation (Chen and Slater, 2015).

Despite the obvious shortcomings of the EBG approach discussed above, it still produced the best match against measured $\mathrm{CH}_{4}$ fluxes with a relatively high coefficient of determination $\left(R^{2}=0.63\right)$. However, the EC system estimated fluxes on an ecosystem scale whereas the model results represent fluxes from a single horizontally homogeneous peat column and hence they are not fully comparable. The EC source area (i.e. footprint) may contain locations where ebullition takes place and locations where at the same time it is absent. Therefore, the ebullition events are presumably averaged with other sources (e.g. plant transport) in the conventionally processed EC fluxes, yet their impact on ecosystem scale fluxes is captured accurately. Hence, while EC does estimate fluxes on a continuous basis, EC-derived fluxes are not a perfect measure of bubble flux from a single peat column. Ideally these kind of models should be tested against autochambers that continuously estimate the $\mathrm{CH}_{4}$ flux on a smaller horizontal scale than EC. Moreover, ebullition events can be detected and quantified from such measurements (e.g. Goodrich et al., 2011) and hence could be directly compared with the modelled ebullition. In addition to autochambers, the models could also be validated against changes in $\mathrm{CH}_{4}$ storage (liquid and gas phase) in the peat since the ebullition modelling approach largely alters the amount of $\mathrm{CH}_{4}$ stored below the surface during the model run (see Fig. 2).

The process-based models are often evaluated by comparing with measurements and possibly optimized to match observed $\mathrm{CH}_{4}$ emissions by minimizing some statistic or objective function, for instance root mean square error (RMSE) (Wania et al., 2010) or Nash-Sutcliffe efficiency (NS) (van Huissteden et al., 2009), or by using, for instance, Markov chain Monte Carlo methods (Susiluoto et al., 2017). Poorly represented processes, for instance ebullition, hinder this comparison and may yield erroneous values for many of the model parameters when the models are calibrated, even though other processes would be described in a realistic manner. This is simply because the poorly described process causes apparent mismatch between models and measurements. This might be especially true for ebullition since it strongly influences $\mathrm{CH}_{4}$ flux time series variance, which in turn has a direct impact on many metrics such as RMSE, NS and $R^{2}$. Hence, slightly more realistic ebullition modelling, such as the EBG approach, would allow better tuning of the $\mathrm{CH}_{4}$ models and ultimately more accurate $\mathrm{CH}_{4}$ emission estimates.

Finally it should be mentioned that there is also merit in simplicity. While the ECT approach lacks feedback to many ebullition drivers (e.g. pressure changes), the approach is simple and hence adds only a minimal number of degrees of freedom to the model and therefore possibly provides more robust modelling results. The approach could be further modified to take into account the fact that bubbles do not consist $100 \%$ of $\mathrm{CH}_{4}$ (e.g. Riley et al., 2011) in order to make it more realistic. Conversely, the merit of the EPT approach, in addition to being simple, is that it does not use a predefined $\mathrm{CH}_{4}$ mixing ratio in the bubbles and hence it is a viable modelling approach for models that also explicitly calculate $\mathrm{CO}_{2}$ and $\mathrm{O}_{2}$ concentrations in the peat column.

\section{Conclusions}

In this study three approaches to model $\mathrm{CH}_{4}$ transport via bubbling, i.e. ebullition, were compared by implementing them in one peatland $\mathrm{CH}_{4}$ cycling model called HIMMELI. The model was run using forcing data from a boreal sedge fen. The study was motivated by the fact that ebullition is modelled rather crudely in many models and hence there is clearly a need for improvement and comparison of methods. All three approaches were based on thresholding on some variable, either pore water $\mathrm{CH}_{4}$ concentration (ECT approach), pressure (EPT) or free-phase gas volume (EBG). The ECT approach is commonly used in process-based $\mathrm{CH}_{4}$ models even though it describes the physical processes behind ebullition in a simplistic manner, whereas the EBG approach most closely resembles the current knowledge of the process.

EPT simulated the highest number of ebullition events and hence produced the highest ebullition $\mathrm{CH}_{4}$ fluxes to the surface. All the modelling approaches triggered ebullition events only well below the surface, which was caused by the effect of vascular plant root distribution on pore water $\mathrm{CH}_{4}$ concentrations. The modelled $\mathrm{CH}_{4}$ fluxes were also compared with eddy covariance measurements of $\mathrm{CH}_{4}$ fluxes and EBG produced the best match against measurements $\left(R^{2}=0.63\right)$, although a horizontal scale mismatch is evident between the model results (single peat column) and EC measurements (ecosystem scale). EBG incorporates most of the ebullition drivers observed in different studies (temperature, pressure, $\mathrm{CH}_{4}$ production, water level changes), whereas the other modelling approaches, especially ECT, are missing a link to many of the drivers listed. While a simple modelling approach, such as ECT, may yield robust results without many tunable parameters, overly simplified processes in models may hinder model comparison with measurements. Hence modellers and researchers are encouraged to incorporate a realistic description of the ebullition pathway to their models.

Code and data availability. Code and data availability. The Fortran codes describing the EBG modelling approach are included in the Supplement. The HIMMELI model codes are included in the supplement of Raivonen et al. (2017) (https://doi.org/10.5194/ 
gmd-10-4665-2017-supplement). The data used in this study are available online at https://doi.org/10.5281/zenodo.1164760 (Peltola et al., 2018), as well as in the AVAA - open research data publishing platform (http://openscience.fi/avaa).

\section{The Supplement related to this article is available online at https://doi.org/10.5194/bg-15-937-2018-supplement.}

Competing interests. The authors declare that they have no conflict of interest.

Acknowledgements. We want to acknowledge all the researchers who have contributed in the development of the HIMMELI model and also the researchers and technical staff who have continuously maintained measurements at the Siikaneva peatland site. The study was supported by the National Centre of Excellence (272041), ICOS-Finland (281255), CARB-ARC (286190) and academy professor project (284701) funded by the Academy of Finland and AtMath funded by the University of Helsinki.

Edited by: Alexey V. Eliseev

Reviewed by: Nigel Roulet and Jorge Ramirez

\section{References}

Arah, J. R. M. and Stephen, K. D.: A model of the processes leading to methane emission from peatland, Atmos. Environ., 32, 32573264, https://doi.org/10.1016/S1352-2310(98)00052-1, 1998.

AVAA: Open research data publishing platform, available at: http: //openscience.fi/avaa.

Baird, A. J., Beckwith, C. W., Waldron, S., and Waddington, J. M.: Ebullition of methane-containing gas bubbles from nearsurface Sphagnum peat, Geophys. Res. Lett., 31, L21505, https://doi.org/10.1029/2004GL021157, 2004.

Bon, C. E., Reeve, A. S., Slater, L., and Comas, X.: Using hydrologic measurements to investigate free-phase gas ebullition in a Maine peatland, USA, Hydrol. Earth Syst. Sci., 18, 953-965, https://doi.org/10.5194/hess-18-953-2014, 2014.

Chanton, J. P.: The effect of gas transport on the isotope signature of methane in wetlands, Org. Geochem., 36, 753-768, https://doi.org/10.1016/j.orggeochem.2004.10.007, 2005.

Chen, X. and Slater, L.: Gas bubble transport and emissions for shallow peat from a northern peatland: The role of pressure changes and peat structure, Water Resour. Res., 51, 151-168, https://doi.org/10.1002/2014WR016268, 2015.

Christensen, T. R., Panikov, N., Mastepanov, M., Joabsson, A., Stewart, A., Öquist, M., Sommerkorn, M., Reynaud, S., and Svensson, B.: Biotic controls on $\mathrm{CO}_{2}$ and $\mathrm{CH}_{4}$ exchange in wetlands - a closed environment study, Biogeochemistry, 64, 337354, https://doi.org/10.1023/a:1024913730848, 2003.

Comas, X., Slater, L., and Reeve, A. S.: Atmospheric pressure drives changes in the vertical distribution of biogenic free-phase gas in a northern peatland, J. Geophys. Res.-Biogeosci., 116, G04014, https://doi.org/10.1029/2011JG001701, 2011.
Coulthard, T. J., Baird, A. J., Ramirez, J., and Waddington, J. M.: Methane Dynamics in Peat: Importance of Shallow Peats and a Novel Reduced-Complexity Approach for Modeling Ebullition, in: Carbon Cycling in Northern Peatlands, edited by: Baird, A. J., Belyea, L. R., Comas, X., Reeve, A. S., and Slater, L. D., Geophysical Monograph Series, Amer Geophysical Union, Washington, 173-185, 2009.

Drebs, A., Nordlund, A., Karlsson, P., Helminen, J., and Rissanen, P.: Climatological statistics of Finland 1971-2000, Book, Whole, Finnish Meteorological Institute, Helsinki, 98 pp., 2002.

Epstein, P. S. and Plesset, M. S.: ON THE STABILITY OF GAS BUBBLES IN LIQUID-GAS SOLUTIONS, J. Chem. Phys., 18, 1505-1509, https://doi.org/10.1063/1.1747520, 1950.

Fechner-Levy, E. J. and Hemond, H. F.: Trapped methane volume and potential effects on methane ebullition in a northern peatland, Limnol. Oceanogr., 41, 1375-1383, https://doi.org/10.4319/lo.1996.41.7.1375, 1996.

Glaser, P. H., Chanton, J. P., Morin, P., Rosenberry, D. O., Siegel, D. I., Ruud, O., Chasar, L. I., and Reeve, A. S.: Surface deformations as indicators of deep ebullition fluxes in a large northern peatland, Global Biogeochem. Cy., 18, GB1003, https://doi.org/10.1029/2003GB002069, 2004.

Goodrich, J. P., Varner, R. K., Frolking, S., Duncan, B. N., and Crill, P. M.: High-frequency measurements of methane ebullition over a growing season at a temperate peatland site, Geophys. Res. Lett., 38, L07404, https://doi.org/10.1029/2011GL046915, 2011.

Granberg, G., Ottosson-Löfvenius, M., Grip, H., Sundh, I., and Nilsson, M.: Effect of climatic variability from 1980 to 1997 on simulated methane emission from a boreal mixed mire in northern Sweden, Global Biogeochem. Cy., 15, 977-991, https://doi.org/10.1029/2000GB001356, 2001.

Grant, R. F.: Simulation of methanogenesis in the mathematical model ecosys, Soil Biol. Biochem., 30, 883-896, https://doi.org/10.1016/S0038-0717(97)00218-6, 1998.

Green, S. M. and Baird, A. J.: A mesocosm study of the role of the sedge Eriophorum angustifolium in the efflux of methane including that due to episodic ebullition - from peatlands, Plant Soil, 351, 207-218, https://doi.org/10.1007/s11104-011-0945-1, 2012.

Hari, P. and Kulmala, M.: Station for measuring ecosystematmosphere relations (SMEAR II), Boreal Environ. Res., 10, 315-322, 2005.

Kellner, E., Baird, A. J., Oosterwoud, M., Harrison, K., and Waddington, J. M.: Effect of temperature and atmospheric pressure on methane $\left(\mathrm{CH}_{4}\right)$ ebullition from near-surface peats, Geophys. Res. Lett., 33, L18405, https://doi.org/10.1029/2006GL027509, 2006.

Klapstein, S. J., Turetsky, M. R., McGuire, A. D., Harden, J. W., Czimczik, C. I., Xu, X., Chanton, J. P., and Waddington, J. M.: Controls on methane released through ebullition in peatlands affected by permafrost degradation, J. Geophys. Res.-Biogeosci., 119, 418-431, https://doi.org/10.1002/2013JG002441, 2014.

Le Mer, J. and Roger, P.: Production, oxidation, emission and consumption of methane by soils: A review, Eur. J. Soil Biol., 37, 25-50, https://doi.org/10.1016/S1164-5563(01)01067-6, 2001.

Mammarella, I., Peltola, O., Nordbo, A., Järvi, L., and Rannik, Ü.: Quantifying the uncertainty of eddy covariance fluxes due to the use of different software packages and combinations of process- 
ing steps in two contrasting ecosystems, Atmos. Meas. Tech., 9, 4915-4933, https://doi.org/10.5194/amt-9-4915-2016, 2016.

Moore, T., Roulet, N., and Knowles, R.: Spatial and temporal variations of methane flux from subarctic/northern boreal fens, Global Biogeochem. Cy., 4, 29-46, https://doi.org/10.1029/GB004i001p00029, 1990.

Peltola, O., Mammarella, I., Haapanala, S., Burba, G., and Vesala, T.: Field intercomparison of four methane gas analyzers suitable for eddy covariance flux measurements, Biogeosciences, 10 , 3749-3765, https://doi.org/10.5194/bg-10-3749-2013, 2013.

Peltola, O., Raivonen, M., Li, Xu., and Vesala, T.: Dataset for "Technical Note: Comparison of methane ebullition modelling approaches used in terrestrial wetland models [Data set], Zenodo, https://doi.org/10.5281/zenodo.1164760, 2018.

Raivonen, M., Smolander, S., Backman, L., Susiluoto, J., Aalto, T., Markkanen, T., Mäkelä, J., Rinne, J., Peltola, O., Aurela, M., Lohila, A., Tomasic, M., Li, X., Larmola, T., Juutinen, S., Tuittila, E.-S., Heimann, M., Sevanto, S., Kleinen, T., Brovkin, V., and Vesala, T.: HIMMELI v1.0: HelsinkI Model of MEthane buiLdup and emIssion for peatlands, Geosci. Model Dev., 10, 46654691, https://doi.org/10.5194/gmd-10-4665-2017, 2017.

Ramirez, J. A., Baird, A. J., Coulthard, T. J., and Waddington, J. M.: Testing a simple model of gas bubble dynamics in porous media, Water Resour. Res., 51, 1036-1049, https://doi.org/10.1002/2014WR015898, 2015.

Ramirez, J. A., Baird, A. J., and Coulthard, T. J.: The effect of pore structure on ebullition from peat, J. Geophys. Res.-Biogeosc., 121, 1646-1656, https://doi.org/10.1002/2015JG003289, 2016.

Riley, W. J., Subin, Z. M., Lawrence, D. M., Swenson, S. C., Torn, M. S., Meng, L., Mahowald, N. M., and Hess, P.: Barriers to predicting changes in global terrestrial methane fluxes: analyses using CLM4Me, a methane biogeochemistry model integrated in CESM, Biogeosciences, 8, 1925-1953, https://doi.org/10.5194/bg-8-1925-2011, 2011.

Rinne, J., Riutta, T., Pihlatie, M., Aurela, M., Haapanala, S., Tuovinen, J. P., Tuittila, E. S., and Vesala, T.: Annual cycle of methane emission from a boreal fen measured by the eddy covariance technique, Tellus B, 59, 449-457, https://doi.org/10.1111/j.16000889.2007.00261.x, 2007

Riutta, T., Laine, J., Aurela, M., Rinne, J., Vesala, T., Laurila, T., Haapanala, S., Pihlatie, M., and Tuittila, E. S.: Spatial variation in plant community functions regulates carbon gas dynamics in a boreal fen ecosystem, Tellus Series B, 59, 838-852, https://doi.org/10.1111/j.1600-0889.2007.00302.x, 2007.

Rosenberry, D. O., Glaser, P. H., and Siegel, D. I.: The hydrology of northern peatlands as affected by biogenic gas: current developments and research needs, Hydrol. Process., 20, 3601-3610, https://doi.org/10.1002/hyp.6377, 2006.

Sander, R.: Compilation of Henry's law constants (version 4.0) for water as solvent, Atmos. Chem. Phys., 15, 4399-4981, https://doi.org/10.5194/acp-15-4399-2015, 2015.

Schuldt, R. J., Brovkin, V., Kleinen, T., and Winderlich, J.: Modelling Holocene carbon accumulation and methane emissions of boreal wetlands - an Earth system model approach, Biogeosciences, 10, 1659-1674, https://doi.org/10.5194/bg-10-16592013, 2013.

Segers, R., Rappoldt, C., and Leffelaar, P. A.: Modeling methane fluxes in wetlands with gas-transporting plants: 2 .
Soil layer scale, J. Geophys. Res.-Atmos., 106, 3529-3540, https://doi.org/10.1029/2000JD900483, 2001.

Strack, M., Kellner, E., and Waddington, J. M.: Dynamics of biogenic gas bubbles in peat and their effects on peatland biogeochemistry, Global Biogeochem. Cy., 19, GB1003, https://doi.org/10.1029/2004GB002330, 2005.

Ström, L., Ekberg, A., Mastepanov, M., and Røjle Christensen, T.: The effect of vascular plants on carbon turnover and methane emissions from a tundra wetland, Global Change Biol., 9, 11851192, https://doi.org/10.1046/j.1365-2486.2003.00655.x, 2003.

Susiluoto, J., Raivonen, M., Backman, L., Laine, M., Mäkelä, J., Peltola, O., Vesala, T., and Aalto, T.: Calibrating a wetland methane emission model with hierarchical modeling and adaptive MCMC, Geosci. Model Dev. Discuss., https://doi.org/10.5194/gmd-2017-66, in review, 2017.

Tang, J., Zhuang, Q., Shannon, R. D., and White, J. R.: Quantifying wetland methane emissions with process-based models of different complexities, Biogeosciences, 7, 3817-3837, https://doi.org/10.5194/bg-7-3817-2010, 2010.

Tokida, T., Miyazaki, T., and Mizoguchi, M.: Ebullition of methane from peat with falling atmospheric pressure, Geophys. Res. Lett., 32, L13823, https://doi.org/10.1029/2005GL022949, 2005.

Tokida, T., Miyazaki, T., Mizoguchi, M., Nagata, O., Takakai, F., Kagemoto, A., and Hatano, R.: Falling atmospheric pressure as a trigger for methane ebullition from peatland, Global Biogeochem. Cy., 21, GB2003, https://doi.org/10.1029/2006GB002790, 2007.

van Huissteden, J., Petrescu, A. M. R., Hendriks, D. M. D., and Rebel, K. T.: Sensitivity analysis of a wetland methane emission model based on temperate and arctic wetland sites, Biogeosciences, 6, 3035-3051, https://doi.org/10.5194/bg-6-30352009, 2009.

Waddington, J. M., Harrison, K., Kellner, E., and Baird, A. J.: Effect of atmospheric pressure and temperature on entrapped gas content in peat, Hydrol. Process., 23, 2970-2980, https://doi.org/10.1002/hyp.7412, 2009.

Walter, B. P. and Heimann, M.: A process-based, climate-sensitive model to derive methane emissions from natural wetlands: Application to five wetland sites, sensitivity to model parameters, and climate, Global Biogeochem. Cy., 14, 745-765, https://doi.org/10.1029/1999GB001204, 2000.

Walter, K. M., Chanton, J. P., Chapin, F. S., Schuur, E. A. G., and Zimov, S. A.: Methane production and bubble emissions from arctic lakes: Isotopic implications for source pathways and ages, J. Geophys. Res.-Biogeosci., 113, G00A08, https://doi.org/10.1029/2007JG000569, 2008.

Wania, R., Ross, I., and Prentice, I. C.: Implementation and evaluation of a new methane model within a dynamic global vegetation model: LPJ-WHyMe v1.3.1, Geosci. Model Dev., 3, 565-584, https://doi.org/10.5194/gmd-3-565-2010, 2010.

Xu, X., Yuan, F., Hanson, P. J., Wullschleger, S. D., Thornton, P. E., Riley, W. J., Song, X., Graham, D. E., Song, C., and Tian, H.: Reviews and syntheses: Four decades of modeling methane cycling in terrestrial ecosystems, Biogeosciences, 13, 3735-3755, https://doi.org/10.5194/bg-13-3735-2016, 2016. 
Yu, Z., Slater, L. D., Schäfer, K. V. R., Reeve, A. S., and Varner, R. K.: Dynamics of methane ebullition from a peat monolith revealed from a dynamic flux chamber system, J. Geophys. Res.-Biogeosci., 119, 1789-1806, https://doi.org/10.1002/2014JG002654, 2014.
Zhang, Y., Sachs, T., Li, C., and Boike, J.: Upscaling methane fluxes from closed chambers to eddy covariance based on a permafrost biogeochemistry integrated model, Global Change Biol., 18, 1428-1440, https://doi.org/10.1111/j.1365-2486.2011.02587.x, 2012. 